\title{
Melting properties of pyrolite: implication for chemical segregation in the primitive Earth's mantle.
}

\author{
REMY PIERRU $^{1}$, DENIS ANDRAULT ${ }^{1}$, GEETH \\ MANTHILAKE $^{2}$, NICOLAS GUIGNOT ${ }^{3}$, JEAN-PAUL ITIE ${ }^{3}$, \\ ANDREW KING $^{3}$ AND LOUIS HENNET $^{4}$ \\ ${ }^{1}$ Université Clermont Auvergne \\ ${ }^{2}$ Universite Clermont Auvergne \\ ${ }^{3}$ Synchrotron SOLEIL \\ ${ }^{4}$ CNRS Orléans \\ Presenting Author: remy.pierru@uca.fr
}

Planetary materials can melt partially over a wide range of temperatures between their solidus and liquidus. Phase relations and melt compositions of a dry pyrolite have been determined up to $24 \mathrm{GPa}$ and temperatures from $1600 \mathrm{~K}$ to $2400 \mathrm{~K}$. We monitored the melt fraction in our samples using either electricalconductivity measurements at LMV or X-ray diffraction (XRD) at the PSICHE beamline of the SOLEIL synchrotron. The in-situ measurements reveal solidus and liquidus temperature profiles lower than previously reported for a pyrolitic or a chondritic upper mantle ${ }^{2,5}$. In addition, precise chemical analyses performed on the recovered samples enable the determination of mineral and melt compositions as a function of pressure and temperature.

Major implications concern the magma ocean crystallization in the early Earth. The solid-liquid phase relations can be modelled as a function of the mantle temperature and, therefore, refine the type of chemical segregation that could have occurred very early on. Thanks to the "falling sphere" technique, we refined the conditions at which the viscous transition occurs in a crystallizing magma ocean. It controls the lifetime of magma oceans and the possibility to induce chemical fractional upon crystallization $^{1,4}$. Much lower melting temperatures and the slowing down of the crystallization of the magma ocean produced by the viscous transition ${ }^{4}$ could explain the presence and the chemical evolution of certain magmas from Archean (Mostly Komatiites...) to Proterozoic (Komatiites, Kimberlites, Picrites, basalts...). Based on a new phase diagram, we propose a model to explain the chemical segregation in a crystalizing pyrolitic upper mantle to discuss the origins of LIPS through time.

References:

1 Solomatov, V. S. in Treatise on Geophysics Vol. 9 81-104 (Elsevier, 2015).

2 Litasov, K. \& Ohtani, E. Phys. Earth Planet. Inter. 134, $105-$ 127, (2002).

3 Andrault, D. et al. Nat. Geosci. 11, 139-+, (2018).

4 Monteux, J. et al. Earth Planet. Sci. Lett. 448, 140-149, (2016). 